\title{
ENERGY HARVESTING TECHNIQUES IN WIRELESS SENSOR NETWORKS *
}

\author{
$U D C((620.91+681.586): 621.391)$
}

\section{Tatjana Nikolić, Mile Stojčev, Goran Nikolić, Goran Jovanović}

University of Niš, Faculty of Electronic Engineering, Niš, Republic of Serbia

\begin{abstract}
Batteries are the main source of energy for low-power electronics such as micro-electro mechanical systems (MEMS), wireless sensor networks, embedded devices for remote sensing and control, etc. With the limited capacity of finite power sources and the need for supplying energy for the lifetime of a system/device there is a requirement for self-powered devices. Using conventional batteries is not always good design solution because batteries require human intervention to replace them (very often in hard-accessible and harsh-environmental conditions). Therefore, acquiring the electrical power, by using an alternative source of energy that is needed to operate these devices is a major concern. The process of extracting energy from the surrounding environment and converting it into consumable electrical energy is known as energy harvesting or power scavenging. The energy harvesting sources can be used to increase the lifetime and capability of the devices by either replacing or augmenting the battery usage. There are various forms of energy that can be scavenged, like solar, mechanical, thermal, and electromagnetic. Nowadays, there is a big interest in the field of research related to energy harvesting. This paper represents a survey for identifying the sources of energy harvesting and describes the basic operation of principles of the most common energy harvesters. As first, we present, in short, the conversion principles of single energy source harvesting systems and point to their benefits and limitations in their usage. After that, hybrid structures of energy harvesters which simultaneously combine scavenged power from different ambient sources (solar, thermoelectric, electromagnetic), with the aim of supporting higher load at the output, are considered.
\end{abstract}

Key words: energy harvesting, wireless sensor network, duty-cycle, hybrid energy harvester

Received May 30, 2018

Corresponding author: Tatjana R. Nikolić

Faculty of Electronic Engineering, Aleksandra Medvedeva 14, 18000 Niš, Republic of Serbia

E-mail: tatjana.nikolic@elfak.ni.ac.rs

"Acknowledgement: This work was supported by the Serbian Ministry of Science and Technological Development, Project No. TR-32009 - "Low-Power Reconfigurable Fault-Tolerant Platforms". 


\section{INTRODUCTION}

A wireless sensor network (WSN) consists of a number of low-power devices (called sensor nodes (SNs)) equipped with sensing, computing and communicating capabilities [1]. Serious problem faced by WSNs is energy. When an SN is depleted of energy it can no longer fulfill its role unless the source of energy, usually a battery, is replaced. One of the major limitations on performance and lifetime of such WSNs is the limited capacity of these finite power sources, which must be manually replaced when they are depleted. However, manual replacement or recharging of batteries is not an easy and always possible task due to high maintenance cost of replacing batteries for numerous SNs, especially in hard-to-service areas [2], [3]. A promising technique that is commonly applied to address the problem of finite SN lifetime is the use of energy harvesting. Energy harvesting refers to harnessing energy from the environments or other energy sources (body heat, foot strike, finger strokes) and converting it to electrical energy. The harnessed electrical energy powers the SNs. Recent works [4], [5] has explored scenarios in which SNs can harvest energy from their environment (for example, from the sun) and use it to recharge their batteries. In the absence of such energy (e.g., at night in the case of solar energy), SNs can then subsist on their replenished battery supply. The classification of energy harvesting can be organized on the basis of the form of energy the SNs use to scavenge the power. For instance, piezoelectric harvesting devices scavenge mechanical energy and convert it into usable electrical energy. Other common sources for energy scavenging are wind turbines, photovoltaic cells, thermoelectric generators, mechanical devices (e.g., piezoelectric devices), electromagnetic devices, and others [6].

In this paper, we present an overview of the basic energy harvesting techniques that are used in WSNs. Firstly, WSN is defined as a collection of battery powered SNs randomly distributed over an area. Since the battery capacity is limited, and battery replacement is a costly and an often impossible task, in many real WSN applications using harvested energy as alternative/main system power source becomes a necessity. Secondly, the common energy harvesting sources are identified and the amount of energy that can be captured from these sources is presented. After that, the architecture of a SN is described and its essential activities (sensing, data processing and communication) are indicated. With an aim of prolonging the lifespan of an SN and indirectly save energy, the usage of a duty-cycle technique is proposed. Thirdly, in the central part of this paper, a unified understanding of energy harvesting and studying the most common energy sources (light, thermal gradients, vibration, etc.) and their characteristics are provided. For each energy source, a corresponding energy harvester structure is given and its benefits and limitations are indicated. In general, a single harvesting technology suitable for implementation in all applications does not exist. Having this in mind, the last part of our paper describes hybrid energy harvesters in a form of combined usage of complementary power sources (light, vibration, thermal, RF, e.tc.) as efficient design solutions attractive for VLSI implementation as a single chip, in the near future. Our paper is concluded by summarizing the contribution of the paper and suggesting future work.

\section{SENSOR NODE ARCHITECTURE}

A typical hardware structure of an SN is presented in Fig. 1 [7]. The SN consists of several building blocks: 
a) MCU - referred as a processing subsystem, controls the operation of all constituents within the SN and performs data processing. The MCU includes a microcontroller and a memory for local data processing.

b) Sensor Elements (SE) - called a sensing subsystem, implemented as a set of passive and active sensors (digital or analog) convert the input information from the external environment into electrical signals. In most applications, wireless SNs are used for monitoring light, pressure, vibration, flow rates in pipelines, temperature, ventilation, electricity, etc. Commonly, sensor elements generate voltage or current signals at their outputs. These signals are first amplified (conditioned) and then digitized with an analogto-digital converter, ADC, before data are digitally processed, stored and transmitted.

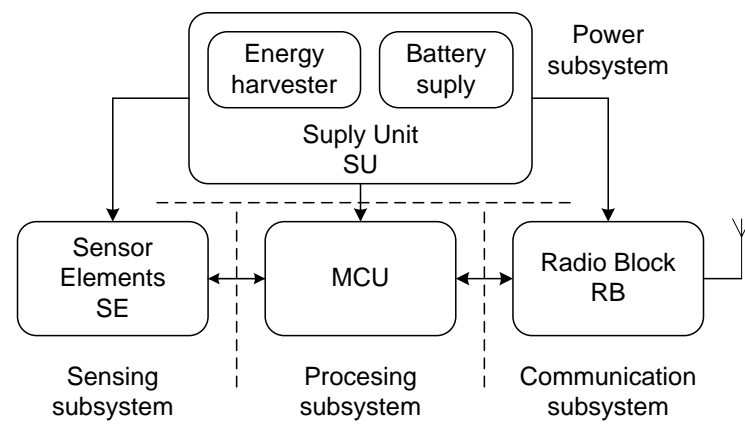

Fig. 1 Typical block scheme of a sensor node

c) Radio Block (RB) - implemented as a short range transceiver which provides wireless communication with the host or SNs within a WSN.

d) Supply Unit (SU) - is a part of the power subsystem acting as a controllable unit which individually switches on/off the power supply of each of SN's building blocks. SU is responsible for providing the right amount of supply voltage to each individual SN hardware component.

\subsection{Power Consumption of Sensor Nodes}

In general, in terms of power consumption, sensor nodes can be categorized into four groups, as it is presented in Table 1 [6], [8].

Table 1 Categorization of sensor nodes into four distinct groups

\begin{tabular}{|c|c|c|}
\hline Category & Power range & Applications \\
\hline ultra-low power & $\leq 1 \mathrm{~mW}$ & $\begin{array}{l}\text { environmental monitoring, smart homes, surveillance; two } \\
\text { operational modes: a) fully-operational (consumption is of } \\
\text { order } \mathrm{mW} \text { ), and b) standby (consumption is of order } \mathrm{pW} \text { ) }\end{array}$ \\
\hline low-power & $1 \mathrm{~mW}-1 \mathrm{~W}$ & $\begin{array}{l}\text { machine interface, structural health monitoring, smart } \\
\text { transportation (consumption varies from } 100 \mu \mathrm{W} \text { up to } 1 \mathrm{~W} \text { ) }\end{array}$ \\
\hline medium-power & $1 \mathrm{~W}-10 \mathrm{~W}$ & $\begin{array}{l}\text { gas sensors, camera, Internet gateways in WSN (provide high } \\
\text { data rate transmission and execute complicated routing } \\
\text { algorithms); (consumption varies from } 500 \mathrm{~mW} \text { up to } 10 \mathrm{~W} \text { ) }\end{array}$ \\
\hline high-power & $\geq 10 \mathrm{~W}$ & $\begin{array}{l}\text { grid connected devices, household-devices, industrial systems } \\
\text { (power consumption varies from } 5 \mathrm{~W} \text { up to } 5 \mathrm{~kW} \text { ) }\end{array}$ \\
\hline
\end{tabular}


In order to save energy, the sensor nodes use two different modes of operation: active and sleep. The power consumption of a typical SN's building block (see Fig. 1) is given in Table 2 [7].

Table 2 Power consumption of different components when the supply voltage is $V_{d d}=3.3 \mathrm{~V}$

\begin{tabular}{lll}
\hline Building block & Power & Mode of operation \\
\hline Processor\&memory\&sensors & $6 \mathrm{~mW}$ & Active mode \\
Processor\&memory\&sensors & $17 \mu \mathrm{W}$ & Sleep mode \\
Radio RX mode & $62 \mathrm{~mW}$ & Active mode (receiving) \\
Radio TX mode & $57 \mathrm{~mW}$ & Active mode (transmission) \\
Radio Idle mode & $69 \mu \mathrm{W}$ & Idle mode (part of the Rx\&Tx logic is active) \\
Radio Sleep mode & $3 \mu \mathrm{W}$ & Sleep mode \\
\hline
\end{tabular}

Duty-cycling is a common approach for reduction of the average energy consumption of SNs. In WSNs, low duty-cycled operation is implemented such that each sensor node periodically switches between the sleeping mode and active mode. If we denote the portion of time in active state as $T_{a c}$ and the period in the sleep state as $T_{s l}$, the duty-cycle $\delta$ can be defined as [9]:

$$
\delta=T_{a c} /\left(T_{a c}+T_{s l}\right), \text { and } 0 \leq \delta \leq 1
$$

For example, if a sensor node requires $3.3 \mathrm{~V}$ at approximately $21 \mathrm{~mA}(70 \mathrm{~mW})$ while active but is only active for 10 milliseconds out of every second, then the average power required is only $0.7 \mathrm{~mW}$. If the same wireless sensor node samples and transmits now once a minute instead of once a second, the average power consumption plummets under $12 \mu \mathrm{W}$. This difference is significant because most types of energy harvesters can offer such low steady-state power, usually no more than a few milliwatts and, in some cases, only microwatts. The less average power required by an application, the more likely it can be powered by harvested energy. As conclusion, by using a combination of duty cycling and energy harvesting techniques significant power consumption reduction (three orders of magnitudes) can be achieved.

Having in mind the aforementioned, it is evident that implementation of an energy harvesting block within the SN's architecture is justified. One general SN architecture which includes the energy harvester block is presented in Fig. 2 [5].

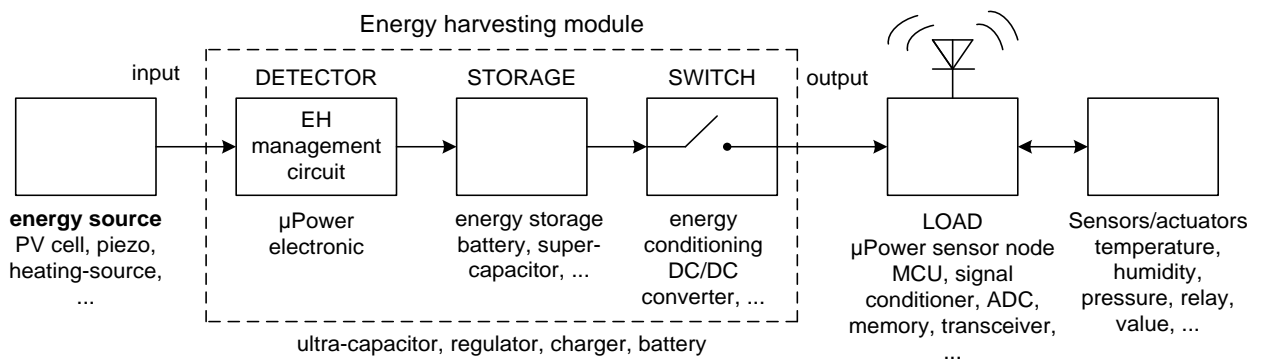

Fig. 2 SN architecture with an energy harvester block

In the following text the focus will be on explaining the principles of operation of different energy harvesters. 


\section{COMMON ENERGY HARVESTING SOURCES}

The mass-production of ultra-low power wireless SNs and embedded systems for measurement and control, along with advances in transducer technology, have made it possible to produce completely autonomous systems that are powered by local ambient energy instead of a primary or a secondary battery. Powering an SN from an ambient or free energy source is attractive because it can be a supplement or it can eliminate the need for batteries or wires. This is a clear benefit when battery replacement or servicing is inconvenient, labor intensive, and costly. In such cases, energy harvesting from any ambient source can readily be used in remote applications where the natural energy is essentially inexhaustible. The classification of energy harvesting can be organized on the basis of the form of energy they use to scavenge the power [5].

The main energy-harvesting sources currently deployed in WSN are the following:

1. Thermal-energy - wasted energy produced by heaters, furnaces, and others, is used.

2. Light-energy - captured energy from sunlight or room lighting

3. Mechanical-energy - energy from sources such as vibration, mechanical stress, etc.

4. Electromagnetic-energy - energy from radio-frequency (RF) radiation, etc.

5. Natural-ambient-energy - energy from wind, water-flow, etc.

6. Human-body-energy - combination of mechanical and thermal energy.

7. Other-energy - energy from chemical and biological sources.

The amount of energy that can be captured from some typical sources is shown in Fig. 3 in the form of $\mu \mathrm{W} / \mathrm{cm}^{2}$ or $\mu \mathrm{W} / \mathrm{cm}^{3}$, depending if it is used as 2D- or 3D harvester [5].

The energy sources are characterized by different power densities (Fig. 3). Energy Harvesting $(\mathrm{EH})$ from outside sun is clearly the most powerful. Unfortunately, solar energy harvesting is not possible in dark areas (near or inside machines, in warehouses). And similarly, it is not possible to harvest energy from thermal gradients where there is no thermal gradient or to harvest vibrations where there is no vibration. As a consequence, the source of ambient energy must be chosen according to the local environment of the SN: no universal ambient energy source exists [10].

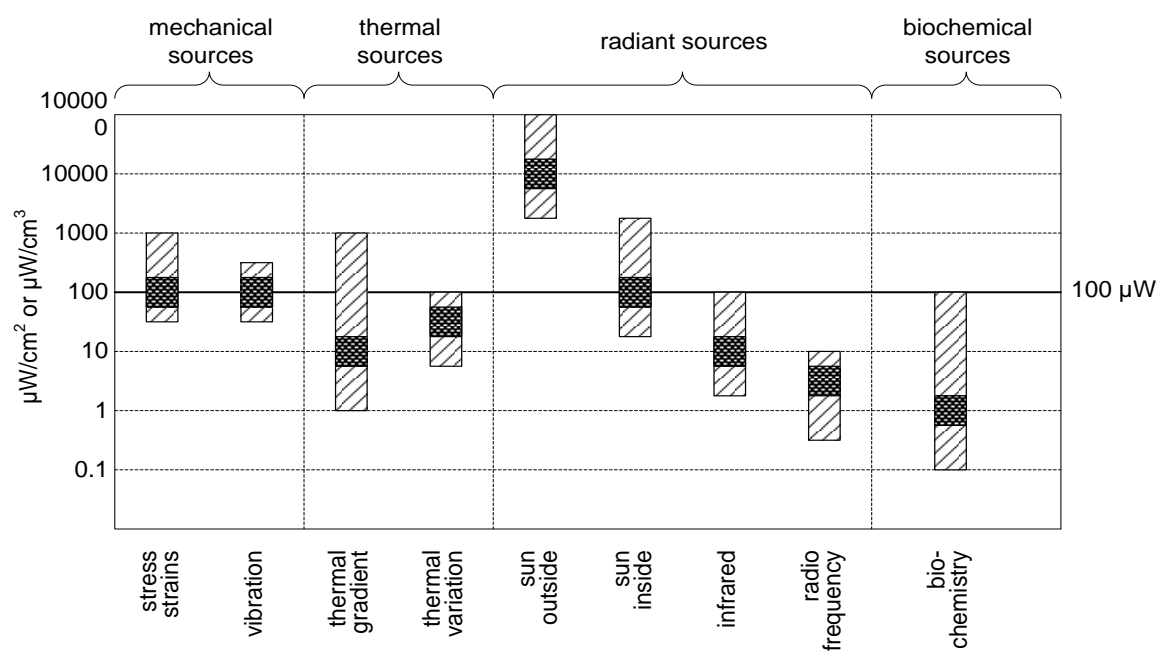

Fig. 3 The harvestable energy sources and the amount of energy they generate 
Efficiency of the energy harvester can be divided into several parts: conversion efficiency from one form of energy to another (e.g., from light to electricity), transfer efficiency from the source to the supply, buffering efficiency once it has been harvested, and consumption efficiency in terms of the amount of useful work given the harvestable energy. The power output from various energy harvesting technologies and corresponding efficiencies, for some typical harvesters, are given in Table 3 [11].

Table 3 Power output from various energy harvesting technologies

\begin{tabular}{|c|c|c|c|}
\hline Harvesting technology & $\begin{array}{l}\text { Power Density } \\
\text { (Harvested power) }\end{array}$ & Characteristics & Efficiency \\
\hline Solar cells - direct sun & $15 \mathrm{~mW} / \mathrm{cm}^{2}$ & Outdoor & $10-41 \%$ \\
\hline Solar cells - cloudy day & $0,15 \mathrm{~mW} / \mathrm{cm}^{2}$ & Outdoor & \\
\hline Solar cells - indoors & $0,006 \mathrm{~mW} / \mathrm{cm}^{2}$ & Indoor & \\
\hline Solar cells - desk lamp $<60 \mathrm{~W}$ & $0,57 \mathrm{~mW} / \mathrm{cm}^{2}$ & Indoor & \\
\hline Piezoelectric - shoe inserts & $330 \mu \mathrm{W} / \mathrm{cm}^{2}$ & $\sim$ Hz-human & $25-50 \%$ \\
\hline Vibration - microwave oven & $0,01-0,1 \mathrm{~mW} / \mathrm{cm}^{2}$ & $\sim$ kHz-machines & \\
\hline Thermoelectric $-10^{\circ} \mathrm{C}$ gradient & $40 \mu \mathrm{W} / \mathrm{cm}^{2}$ & Human, Industrial & $0.1-3 \%$ \\
\hline Passive-human powered system & $1,8 \mathrm{~mW}$ & Human & $1-3 \%$ \\
\hline Radio frequency (RF) & $\begin{array}{l}0.1 \mu \mathrm{W} / \mathrm{cm}^{2} \\
0.001 \mu \mathrm{W} / \mathrm{cm}^{2}\end{array}$ & External & $\begin{array}{l}\text { GSM } 900 \mathrm{MHz} \\
\mathrm{WiFi} 2.4 \mathrm{GHz}\end{array}$ \\
\hline
\end{tabular}

Table 4 A comparison of power sources for SNs

\begin{tabular}{|c|c|c|c|}
\hline Power source & Type & Transducer & Comments \\
\hline wind & mechanical & wind turbine & power density is dependent on wind speed \\
\hline solar & electromagnetic & $\begin{array}{l}\text { solar panel } \\
\text { (outdoors) }\end{array}$ & $\begin{array}{l}\text { solar panel can be scaled to provide higher or } \\
\text { lower power }\end{array}$ \\
\hline thermal & thermal & $\begin{array}{l}\text { thermoelectric } \\
\text { generator }\end{array}$ & $\begin{array}{l}\text { power density is commonly reported for } \\
\text { temperature difference } \Delta \mathrm{T}=10{ }^{\circ} \mathrm{C} \text {, higher } \\
\text { densities can be achieved by increasing } \Delta \mathrm{T}\end{array}$ \\
\hline \multirow[t]{3}{*}{ vibration } & mechanical & electromagnetic & $\begin{array}{l}\text { generated power is dependent on the } \\
\text { amplitude and frequency of mechanical } \\
\text { stimulus of the generator }\end{array}$ \\
\hline & mechanical & $\begin{array}{l}\text { piezoelectric } \\
\text { material }\end{array}$ & $\begin{array}{l}\text { power is determined by the type of the } \\
\text { piezoelectric material and the intensity of the } \\
\text { mechanical stress }\end{array}$ \\
\hline & mechanical & electrostatic & $\begin{array}{l}\text { generated power is dependent on mechanical } \\
\text { stimuli and the fabrication process }\end{array}$ \\
\hline indoor light & electromagnetic & $\begin{array}{l}\text { solar panel } \\
\text { (indoors) }\end{array}$ & $\begin{array}{l}\text { generated power is dependent on the light } \\
\text { intensity and ambient temperature }\end{array}$ \\
\hline directed RF & electromagnetic & Antenna & $\begin{array}{l}\text { the power caster is located in proximity of the } \\
\text { power harvester(s) and aimed at certain } \\
\text { direction to transmit the RF (radio frequency) } \\
\text { signal }\end{array}$ \\
\hline ambient RF & electromagnetic & Antenna & $\begin{array}{l}\text { power density is highly dependent on the } \\
\text { distance from the broadcasting station, type of } \\
\text { the antenna, and the frequency band of the wave }\end{array}$ \\
\hline
\end{tabular}




\subsection{Types of energy harvesters}

The appropriate energy harvesting approach for a WSN is primarily determined by the power requirements of the target applications. These requirements along with the most commonly harvested ambient sources can be categorized and compared in Table 4. The various sources of energy harvesting are wind turbines, photovoltaic cells, thermoelectric generators, vibration devices (such as piezoelectric devices), electromagnetic devices, etc. Table 4 shows some of the harvesting methods with their generation capability [6].

\section{HARVESTING ARCHITECTURE}

The general architecture structure of a typical energy harvester is given in Fig. 4. It consists of the following four building blocks: (i) power sources, (ii) pre-conditioner, (iii) harvester, and (iv) energy buffer. Some of these building blocks may not exist in all types of harvesters; for example, pre-conditioning is not necessary for most of the solar harvesters. We will now describe in short the role of each building block [6].

Power sources: this component comprises the harvestable source and a transducer to convert it to electrical power. As harvestable sources in WSN can be used solar panels, wind turbines, thermoelectric generators, piezoelectric material, RF energy harvester, etc.

Pre-conditioner: pre-conditioning serves three main purposes: (i) a voltage rectifier turns the AC power inputs to DC, (ii) a multiplexer provides the selection of one of the power inputs, (iii) a voltage limiter constituent prevents the harvesting component from being damaged due to over-voltage.

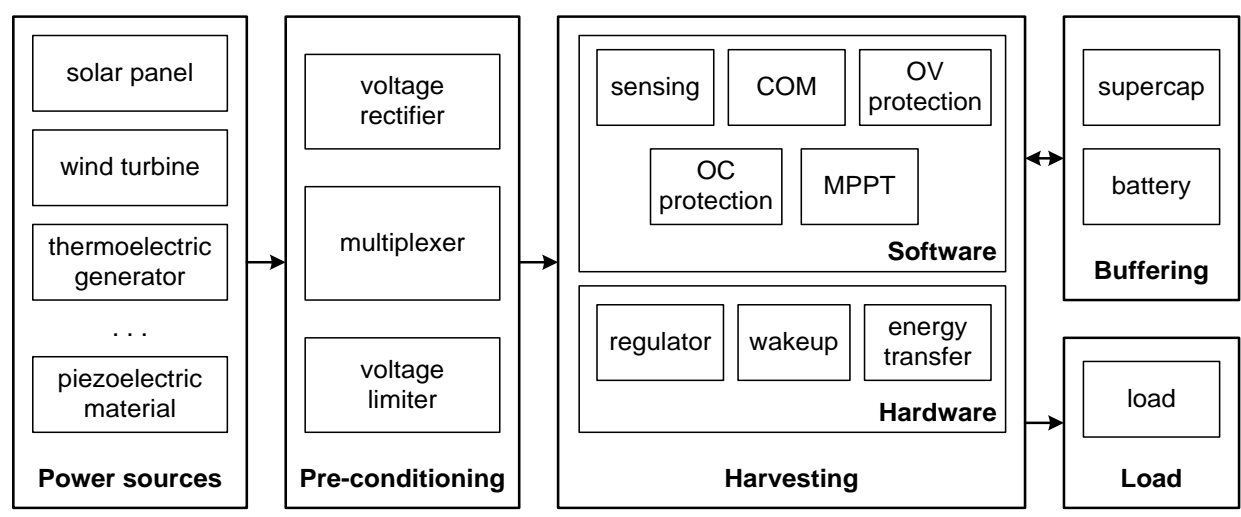

Fig. 4 A general energy harvester

Harvester: this building block is responsible for turning the input power into buffered energy (i.e., harvesting). It can be implemented using basic hardware elements that do not require software to operate (e.g., OPAMPs, comparators, RLC), for greater efficiency, intelligent configurations are typically controlled by firmware running on a microcontroller or a DSP. The harvesting component incorporates the firmware to execute the algorithms, such as the MPPT algorithm. Software-based intelligent harvesters provide additional functionality such as over-voltage protection, voltage regulation, and wireless communication with the other SNs within WSN. 
Energy buffer: buffers the harvested energy. Batteries and supercapacitors are commonly used as buffer elements.

\subsection{Energy harvester for WSNs}

An energy-harvesting system for WSNs represents a simplified version of the general energy harvester given in Fig. 4. As it is presented in Fig. 5, it requires an energy source and some key electronic components to form a complete system [12]. These usually include:

- energy sources or energy conversion device (transducer), such as a piezoelectric element or solar panel that can convert the ambient energy source into an electrical form

- energy harvesting module or electronic interface device (converter), such as a lowvoltage buck-boost converter, to capture energy from a low-voltage source and convert it into a regulated usable voltage to power a load and/or charge a battery or supercapacitor

- sensors, microcontrollers, and a transceiver to read, record, and transmit the data as part of the WSN.

It is very important that SNs have a low quiescent current that allows accumulation of the harvested energy to power these blocks.

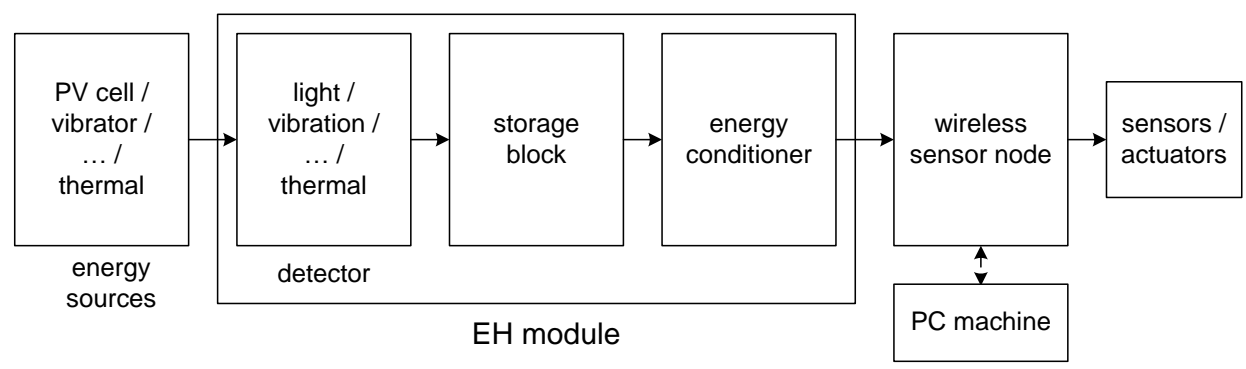

Fig. 5 Single power source energy harvester for SN

Energy harvesting devices can be classified into two ways: a) considering who or what provides the energy for conversion, and b) what type of energy is converted. Table 5 relates the two classification schemes [13].

The first kind of energy harvesting devices is referred as human energy devices. The second kind of energy harvesting devices gets its energy from the environment, and we call them as environment energy devices.

The second classification scheme may consider three types of energy: kinetic, electromagnetic radiation (including light and RF), and thermal.

Table 5 Classes of energy harvesting devices

\begin{tabular}{ll}
\hline Energy Source & Type of Energy \\
\hline Human & Kinetic, Thermal \\
Environment & Kinetic, Thermal, Radiation \\
\hline
\end{tabular}




\subsection{Taxonomy for Energy Harvesting Systems}

A large family of harvesting systems is capable of harvesting energy from one or more power sources. Such systems we call hybrid. To categorize these systems in a concise manner, we introduce a taxonomy that distinguishes each harvesting system based on their power sources. Systems that solely depend on a solar power input are denoted using an S symbol, which means solar-only power input. Similarly, the symbol $\mathrm{W}$ is used to refer to wind energy harvesting systems that depend on a wind-only power input. The symbol $\mathrm{T}$ deals with thermal, $\mathrm{RF}$ relate to radio frequency, and $\mathrm{V}$ refers to vibration energy harvesting systems. To extend this notation to hybrid systems, the notations SW (solar and wind), SS (double solar, sunlight/incandescent), ST (solar and thermal), SV (solar and vibration), SRF (solar and radio frequency), etc., are used.

\section{SOLAR ENERGY HARVESTING (SEH)}

Solar or other light sources are the primary sources for autonomous systems due to the following three reasons:

a) Solar power is readily available everywhere.

b) Solar power transducers provide a higher power density compared to other sources (from $10^{2}$ up to $10^{3}$ higher with respect to RF and thermal).

c) Unlike wind turbines and vibration harvesters, solar energy can be harvested trough solid-state devices with no moving parts, which implies a higher reliability, longer lifetime, and lower maintenance cost.

However, solar energy harvesters (SEHs) have the disadvantage of being able to generate energy only when there is sufficient sunlight or artificial light. In SEH the source of the energy are the photons that the sun generates during the nuclear reaction inside the sun. These photons travel from the sun to the earth in the form of electromagnetic waves and are intercepted by solar panels that turn photons into electrical energy. Table 6 shows the frequency band of the photons that solar panels can harvest [4]. The energy of a photon is

$$
E_{\lambda}=\frac{h c}{\lambda}
$$

where $h$-Planck's constant, $c$ - speed of light in vacuum, $\lambda$-wavelength of the photon.

Table 6 Operational frequency of solar panels [4]

\begin{tabular}{llll}
\hline Radiated frequency & Band name & Wavelength $\lambda$ & Names of electromagnetic wave \\
\hline $270 \mathrm{THz}$ & IR & $1.1 \mu \mathrm{m}$ & infrared \\
$430 \mathrm{THz}$ & $\mathrm{VL}$ & $700 \mathrm{~nm}$ & red (visible light) \\
$\ldots$ & $\ldots$ & $\ldots$ & $\ldots$ \\
$790 \mathrm{THz}$ & $\mathrm{VL}$ & $380 \mathrm{~nm}$ & violet (visible light) \\
$1.6 \mathrm{PHz}$ & $\mathrm{UV}$ & $200 \mathrm{~nm}$ & ultraviolet \\
\hline
\end{tabular}

Solar panels are made out of photo-diodes that have an exposed junction for the photons to hit. When a photon hits an electron of the silicon atom within the photo-diode, it can move a silicon valence electron to conduction and give it sufficient energy to cross 
$\mathrm{p}$-n junction. In this way, the energy that the photon carries is converted to electrical energy. Solar power transducers are composed of elementary units called solar cells (or photo-diodes) that generate electricity from solar radiation. The solar cells are connected in series and/or parallel to form a solar module (or solar panel).

Solar panels (see Fig. 6) can be modeled as a collection of photo-cells with an aggregate current of $I_{p h}$ and a diode $D_{l}$ that has a non-linear intrinsic resistance $R_{l}$, while $R_{2}$ and $R_{3}$ are equivalent shunt and series resistances.

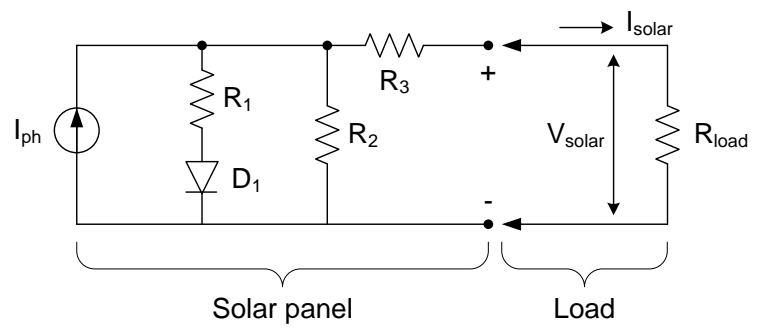

Fig. 6 Equivalent scheme of solar panels

In practical realization $R_{2}$ is very large and $R_{3}$ is relatively small, so that the current $I_{\text {solar }}$ is estimated as

$$
I_{\text {solar }}=I_{p h}-I_{s}\left[\exp \left(\frac{q V_{\text {solar }}}{\alpha k T}\right)-1\right]
$$

where $I_{s}$ is the diode saturation current, $k$ is Boltzmann's constant, $T$ is the junction's temperature in Kelvin, $q$ is the absolute value of electron charge, $\alpha$ is the diode's ideality factor (typically between 1 and 2), and $I_{p h}$ is the aggregate current.

The generated power of a solar panel $\left(P_{\text {solar }}\right)$ is

$$
P_{\text {solar }}=V_{\text {solar }}\left(I_{p h}+I_{s}\right)-I_{s} V_{\text {solar }} \exp \left(\frac{q V_{\text {solar }}}{\alpha k T}\right)
$$

Under varying temperature or irradiance conditions the output characteristics of a photovoltaic (PV) module changes non-linearly (see Fig. 7), i.e. the PV characteristics of solar panels are non-linear and non-monotonic. For each solar irradiation level, the power reaches a global maximum only at a specific voltage (or equivalent current) value, which is the desirable operating point to extract the maximum amount of power from the solar panel. Therefore, the problem is to automatically find the voltage (and the current) at which it should operate to obtain the maximum output power. An efficient photovoltaic energy harvesting system should track this particular operating point is referred to as the Maximum Power Point $(M P P)$. The $M P P$ can be calculated by solving $\left(d P_{\text {solar }} / d P V_{\text {solar }}\right)=0$, which yields the equation

$$
\frac{I_{p h}+I_{s}}{I_{s}}=\left(\frac{q V_{M P P}}{\alpha k T}+1\right) \exp \left(\frac{q V_{M P P}}{\alpha k T}\right)
$$


where $V_{M P P}$ is the solar panel output voltage when it is operating at the MPP. By analyzing Eq. (5) we can conclude that $M P P$ is a function of $I_{p h}$ and $I_{s}$, which depends on instantaneous solar irradiation level (in $\mathrm{W} / \mathrm{m}^{2}$ ) at a given point in time and temperature $T$. In spite of the fact that Eq. (5) provides a basis for accurate MPP tracking, its implementation in harvesting tracking is difficult to conduct because of the need to measure solar irradiation $\left(W_{\text {solar }}\right)$, temperature $(T)$, the voltage $\left(V_{M P P}\right)$ and current $\left(I_{p h}\right)$ of the solar panels. In order to cope efficiently with these problems, which offer simplicity versus accuracy tradeoffs, many designers have actively investigated simplified techniques for MPP tracking (MPPT) [12], [14]. The problem considered by MPPT is to automatically find the operating point at which a PV module should operate to obtain the maximum output power under a given temperature and irradiance, following it when light intensity changes (indicated with arrows in Fig. 7a). A PV module's current versus voltage curve varies with the irradiance or intensity of sunlight. As the graph in Fig. 7b shows, the current dramatically changes as irradiance varies, but voltage remains relatively constant.

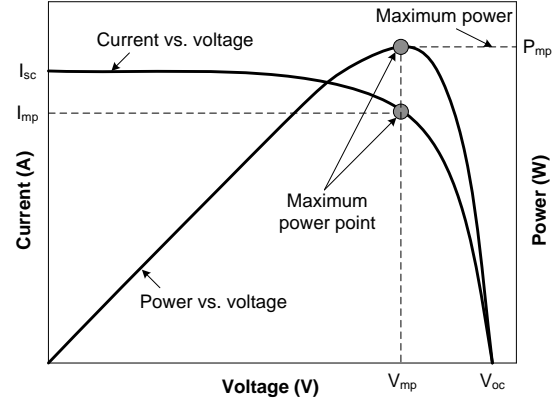

(a)

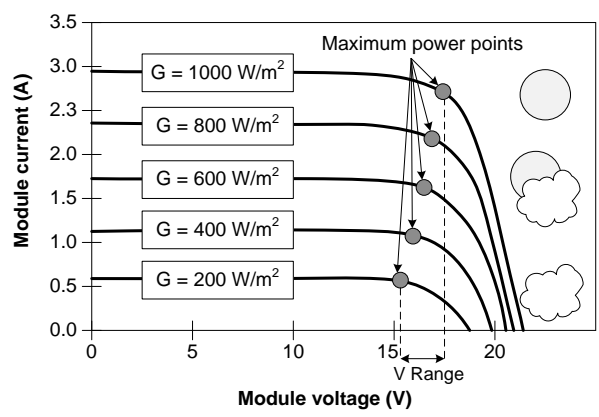

(b)

Fig. 7 PV module: (a) typical current versus voltage (I-V) and power versus voltage $(\mathrm{P}-\mathrm{V})$ curves, (b) current versus voltage curve in term of the irradiance [15]

The magnitude of energy generated by solar cell varies from approximately $15 \mathrm{~mW} / \mathrm{cm}^{2}$ in noon-time sunlight to $10 \mu \mathrm{W} / \mathrm{cm}^{2}$ in indoor incandescent lighting. The energy output depends on the material used. Silicon and gallium arsenide (as crystalline materials) have moderate absorption efficiency (15-30\%), while cadmium telluride (as thin film material) has high absorption efficiency and lower conversion efficiency (10\%). The choice of material depends on its spectral response and the light source of interest. A single solar cell output is $0.6 \mathrm{~V}$ but panels with series of such cells can generate any required voltage.

\subsection{Typical application of SEH}

In Fig. 8, one typical application of solar energy harvester is given. The design solution is based on the LTC3105 which as a complete single chip solution is used for energy harvesting from low cost, single photovoltaic cells. The LTC3105 makes it possible to produce autonomous remote sensor nodes, data collection systems and other applications that require grid independence and minimal maintenance [16]. 


\section{MECHANICAL VIBRATION}

When an embedded device is susceptible to vibration its internal mass can be used to create movement. This movement can be converted into electrical energy. The form of energy utilized in this case is the mechanical energy. Vibrations are available in many environments of interest including commercial buildings, parking structures, aircrafts, trains, industrial facilities and even residential buildings.

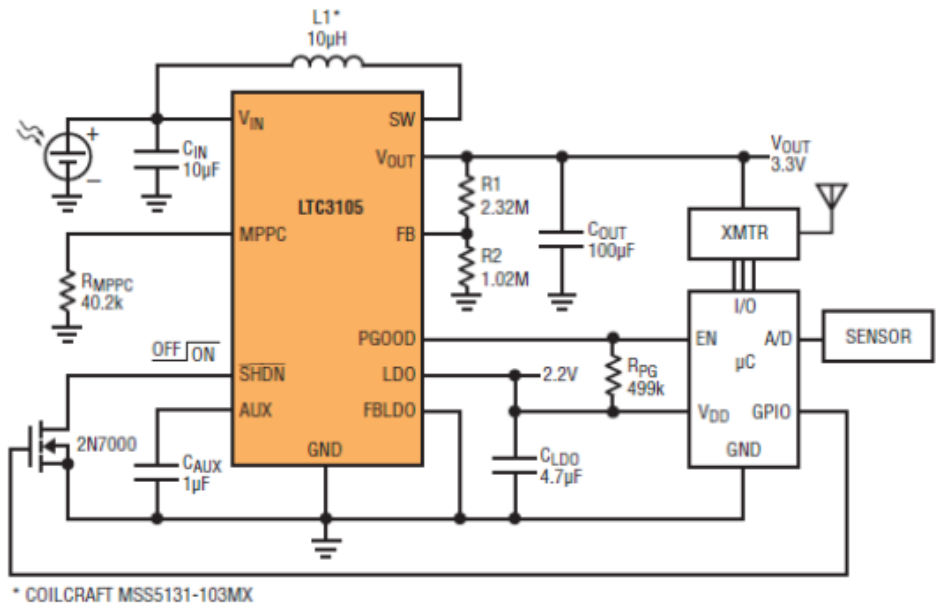

Fig. 8 Simplified schematic of self-powered energy harvesting from PV cell [16]

The sources of vibrations which may be heavy machinery, home appliances, movement of people or vehicles, and other movements vary a great deal in their acceleration characteristics and the frequency spectra. Methods to convert this energy to electricity can be classified into electromagnetic, electrostatic and piezoelectric [4]. Electromagnetic conversion uses vibration to move a conductor in a magnetic field. Existing prototypes generate a very low voltage output to be usable. Electrostatic conversion uses vibration energy to move the conductors of a charged capacitor. The disadvantage of this approach is that a separate voltage source is required to charge the capacitor. An advantage however is that the output voltage is in the usable range of two to several volts. Piezoelectric conversion uses materials which, when mechanically deformed, generate an electric potential. The piezoelectric method combines the advantages of electromagnetic and electrostatic conversion but it is difficult to implement at micro-scale. With the current technology, they have the greatest available energy density among the three methods [10].

\subsection{Piezoelectric materials}

The property to detect vibrations by using piezoelectric material has become viable energy scavenging source. The most commonly used piezoelectric materials are the following: Quartz, Polycrystalline ceramic, Lead Zirconate Titanate (PZT). Using piezoelectric materials to harvest energy requires a mode of storing the energy generated. The energy harvested can be stored in rechargeable batteries instead of using capacitors to store the energy. 
At the circuit level, a single piezo-electric material element is modeled as a voltage source, in series with a capacitor and a resistor. When the material is stressed, an opencircuit voltage develops across the voltage source. When a load is attached, AC excitation energy flows from the element into the loading impedance. Piezo-electric energyharvesting generally yields high voltage levels but low currents.

Fast transients and sinusoidal excitations can be harvested for energy but the energy is not stored in the piezo-electric material itself. Instead, it is stored in a capacitor like mechanism which is connected in parallel with the material. So in practice, when these materials are used for energy-harvesting, a rectifier and a storage element such as a capacitor are used to create usable DC voltages as shown in Fig. 9 [17].

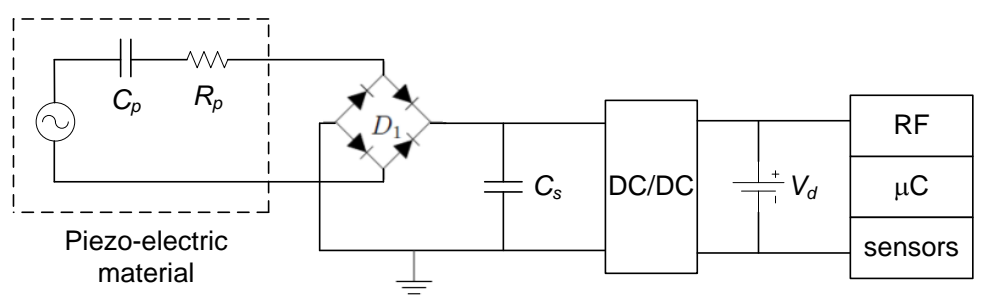

Fig. 9 Generalized piezo-electric energy harvesting circuit

One typical application of piezo-electric energy harvesting circuit based on nanopower energy harvesting power supply unit (product of Linear Technology [18]) is presented in Fig. 10.

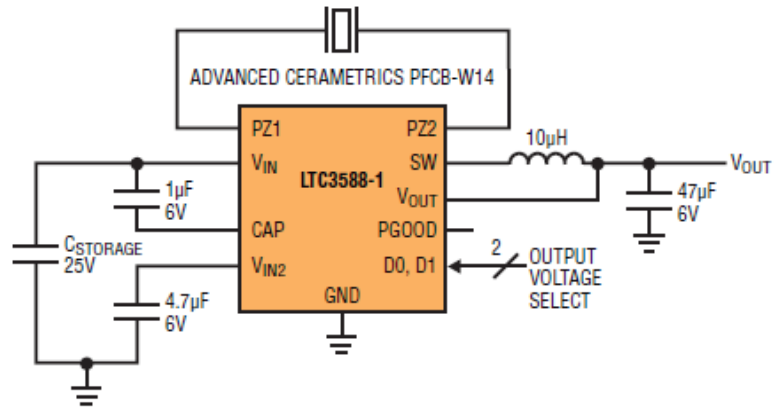

Fig. 10 Piezoelectric energy harvesting power supply [18]

The main advantages of piezoelectric energy harvesters are: a) the direct generation of desired voltage since they do not need a separate voltage source and additional components; b) compatibility with the MEMS; c) high output voltage generation; b) high capacitances; c) no need to control any gap. Disadvantages are the following: a) expensive material; b) coupling coefficient linked to material properties; c) the properties of piezoelectric materials vary with age, stress and temperature [10]. 


\subsection{Electrostatic (Capacitive) Energy Harvesting}

Electrostatic energy harvesting is based on the changing capacitance of vibrationdependent variable capacitors (varactors) to generate charges from a relative motion between two plates. Vibrations separate the plates of an initially charged variable capacitor, and mechanical energy is converted into electrical energy. Electrostatic generators are mechanical devices that produce electricity by using manual power [10]. In Fig. 11 electrostatic converter which uses variable capacitor structure is presented.

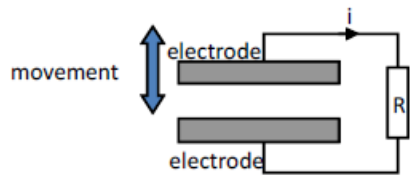

Fig. 11 Electrostatic converter

The significant advantage of using the electrostatic converters is their ability to integrate with microelectronics and they do not need any smart material. In addition, these converters characterize: a) generation of high output voltages; b) possibility to build lowcost systems; c) coupling coefficient easy to adjust; d) high coupling coefficients reachable; e) size reduction increases capacitances. Crucial disadvantages of using electrostatic converters are: a) they need an additional voltage source to initially charge the variable capacitor; b) low capacitances; c) high impact of parasitic capacitances; d) need to control $\mu \mathrm{m}$ dimensions [10].

\subsection{Electromagnetic energy harvesting}

Electromagnetic energy harvesting can be achieved by the principle of electromagnetic induction. Electromagnetic induction is defined as the process of generating voltage in a conductor by changing the magnetic field around the conductor. Namely, they are based on electromagnetic induction and ruled by Lenz's law. An electromotive force is generated from a relative motion between a coil and a magnet. One of the most effective ways of producing electromagnetic induction for energy harvesting is with the help of permanent magnets. Electromagnetic converter which uses Lenz's law is shown in Fig. 12 [10].

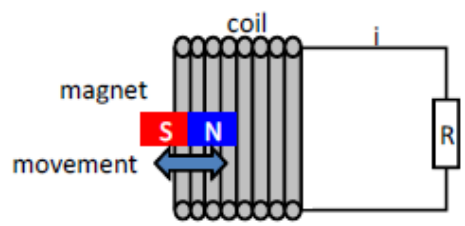

Fig. 12 Electromagnetic converter

Advantages of electromagnetic energy harvesters are: a) high output currents; b) long lifetime proven; and c) robustness. Disadvantages are the following: a) low output voltages; b) hard to develop MEMS devices; c) may be expensive (material); and d) low efficiency in low frequencies and small sizes [10].

As conclusion, the electrostatic and piezoelectric harvesters are capable of producing voltage ranging from 2 to $10 \mathrm{~V}$, whereas the electromagnetic harvesters have a limitation of producing maximum voltage of $0.1 \mathrm{~V}$. 


\section{THERMAL ENERGY HARVESTING}

The thermoelectric effect is a typical example of the conversion of heat energy to electrical energy. Current is generated when there is a temperature difference between two junctions of a conducting material. Thermal energy harvesting uses temperature differences or gradients to generate electricity, e.g. between the human body and the surrounding environment. Devices with direct contact to the human body can harvest the energy radiated from the human body by means of thermoelectric generators (TEGs). Thermoelectric generation using Seebeck effect (flow of current in a loop made from two wires of certain metals when a temperature difference is applied to the wire junctions) and other methods have been demonstrated to yield $10 \mu \mathrm{W} / \mathrm{cm}^{2}$ to $40 \mu \mathrm{W} / \mathrm{cm}^{2}$ using a $5-10$ ${ }^{0} \mathrm{C}$ temperature gradient [19], [20].

Wireless SNs can be powered by temperature gradients. This capability is provided by using TEG which can harvest energy from temperature differentials as low as $2{ }^{\circ} \mathrm{C}$. TEG represents a thermoelectric module that converts a temperature differential across the device into a voltage via the Seebeck effect. The reverse of this phenomenon known as the Peltier effect produces a temperature differential by applying a voltage and is commonly used in thermoelectric coolers (TEGs). The polarity of the generated voltage at the output of TEG depends on the polarity of the temperature differential across the TEG. TEG consists of pairs of n-doped and p-doped semiconductor pellets connected electrically in series and sandwiched between two thermally conductive ceramic plates. The most commonly used semiconductor material is bismuth-telluride $\left(\mathrm{Bi}_{2} \mathrm{Te}_{3}\right)$. The TEG construction is presented in Fig. 13a), its equivalent scheme in Fig. 13b), and the output power in Fig. 13c) [19], [21].
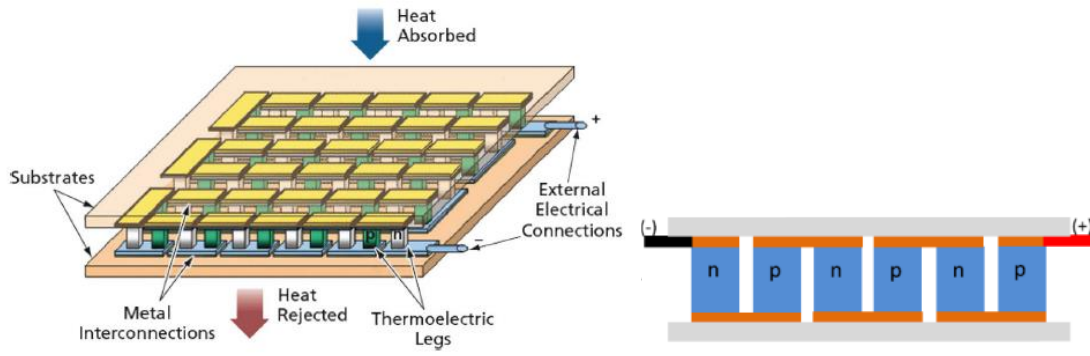

(a)

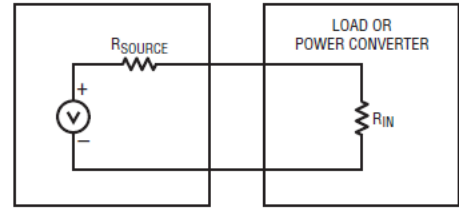

(b)

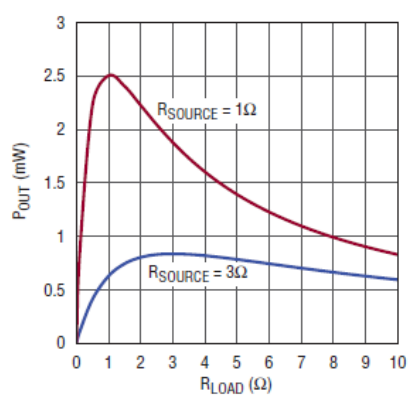

(c)

Fig. 13 A typical thermoelectric generator module: (a) TEG construction; (b) simplified equivalent scheme; (c) output power in terms of load resistance [19], [21] 
Seebeck effect describes the induction of a voltage $V_{S}$ in a circuit consisting of two different conducting materials, whose connections are at different temperatures. In case of a Peltier module the Seebeck voltage can be expressed as in (2), where $T_{h}-T_{c}$ is the temperature gradient across the junctions located at the opposite sides of the module [21].

$$
V_{S}=S_{A B}(\Delta T)=\left(S_{A}-S_{B}\right)\left(T_{h}-T_{c}\right)
$$

where $S_{A}$ and $S_{B}$ are the Seebeck coefficient of the metals A and B, respectively.

Commercially available wireless SN application powered by a TEG is presented in Fig. 14 [22]. Thermoelectric devices are primarily used in space and terrestrial applications. Solid-state thermoelectric generators are considered to have long life, low maintenance and high reliability. The main advantages of this type of generators are that it is a simple structure, there are no moving parts, and it has a relatively long life time (average 20 years). However, their usage is limited because of their low energy conversion efficiency and high costs.

A design example can be found at http://www.linear.com/product/LTC3108. The resulting design can support a $50 \mathrm{~mW}$ load with a duty cycle up to $3.7 \%$

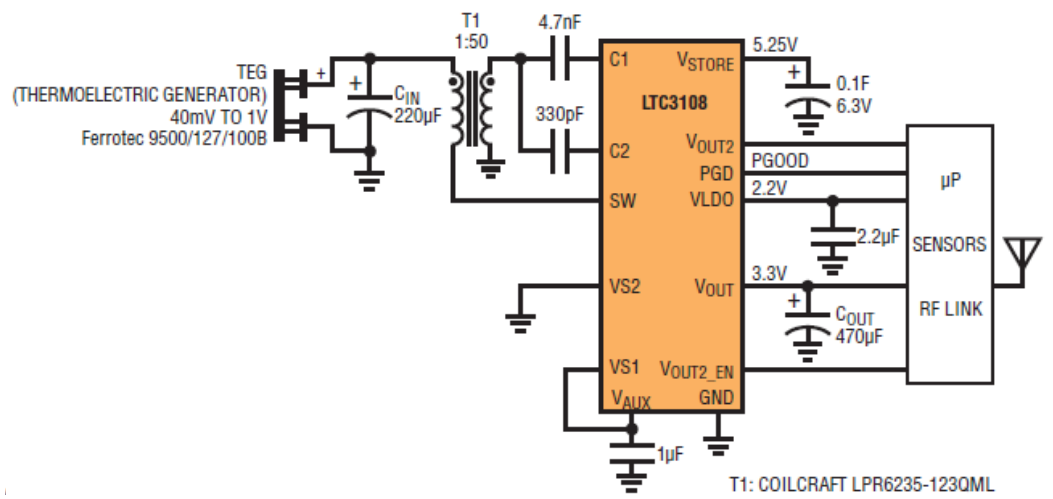

Fig. 14 A wireless SN application powered by a TEG [22]

\section{WIND ENERGY HARVESTING}

Wind or water flow can be converted to energy. While macro-scale generators based on these flows are widely used, compact technologies to extract such energy are lacking.

To harvest wind energy, an electric motor is used, that contains a magnetic rotor. This kind of harvester converts the mechanical energy of the wind into the rotation of the motor, which induces an electromagnetic-force on the rotor. The electromagnetic-force is the harvested energy in the form of an electrical current. The operation of a permanentmagnet wind turbine, which acts as a synchronous generator, is sketched in Fig. 15. As can be seen from Fig. 15 the incoming wind at a speed $v_{\text {wind }}$ has a kinetic power of $P_{u}$. A portion of this power $P_{\text {turbine }}$ is transferred into turbine, causing its blades to turn at an angular velocity of $\mathrm{w}$ and powering the departing wind speed to $v_{d}$ and its kinetic power to $P_{d}$ [6]. In the bottom part of Fig. 15 a per-phase equivalent circuit of a permanent magnet synchronous electric generator is presented. $X_{s}$ and $R_{A}$ represent the stator 
synchronous reactance and its winding resistance, respectively. $R_{L}$ is the equivalent resistance seen by the wind turbine.

Wind turbines are used as the primary power source of SNs in WSN much less frequently than solar panels because:

a) The mechanical operation of wind turbines substantially increases system maintenance.

b) Contrary to solar power for which power availability changes are steady and predictable, wind power changes tend to be much more random.

c) In respect to a solar panel, wind turbines generate an $\mathrm{AC}$ power output requiring rectification circuitry for SNs that operate using DC power.

As a conclusion, in spite of the fact that small scale turbines are available for powering SNs (produce power output in the $\mathrm{mW}$ range) this is much less common than the large wind turbines designed to produce power outputs in the $\mathrm{kW}$ range [23], [6].

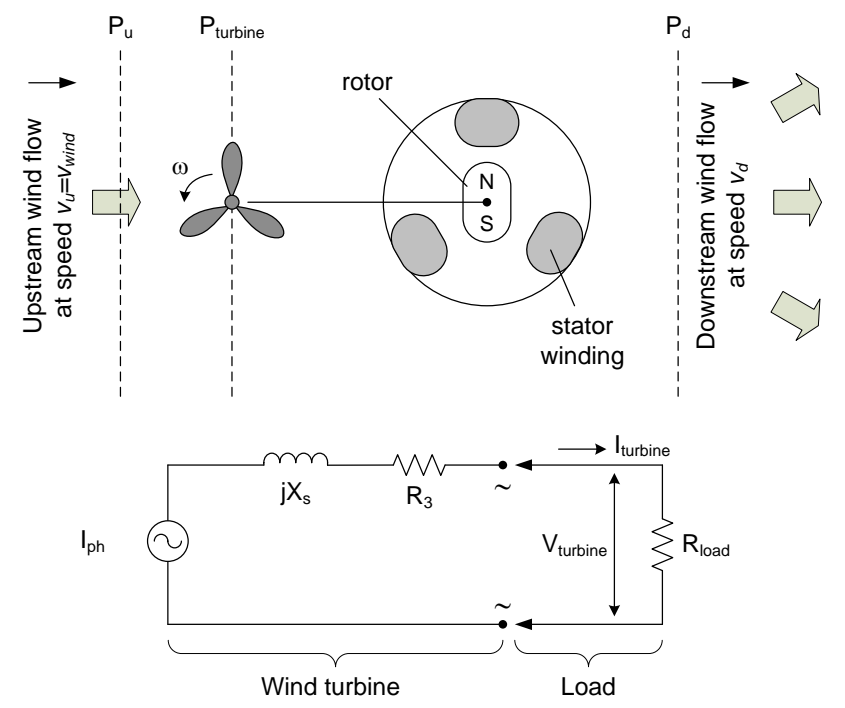

Fig. 15 Operation of a permanent-magnet wind turbine

\section{RADIO-FREQUENCY HARVESTINC}

Radio-frequency (RF) power harvesting refers to the harvesting of the energy in the wireless signal through an antenna to power the SN. RF waves are electromagnetic waves generated by a transmitter in the form of a photon that is oscillating within one of the predetermined frequency band (LF, HF, UHF, SHF, ..., see Table 7) [4]. Let us note now the main difference between RF and solar harvesting. In RF harvesting, the source is an intentional electromagnetic radiation initiated by an electronic device, contrary to the natural radiation initiated by the sun. The most important consequence of this fact is that the electromagnetic properties (radiated frequency, output power) of the RF radiation can be determined by the transmitter. 
Table 7 Commonly used radio-frequencies

\begin{tabular}{llll}
\hline Frequency & Band & Wavelength & Notes \\
\hline $125-134 \mathrm{kHz}$ & LF & $2.3 \mathrm{~km}$ & unregulated \\
$13.56 \mathrm{MHz}$ & $\mathrm{HF}$ & $22 \mathrm{~m}$ & ISM global \\
$865-868 \mathrm{MHz}$ & UHF & $35 \mathrm{~cm}$ & EU:ISM \\
$902-928 \mathrm{MHz}$ & UHF & $33 \mathrm{~cm}$ & USA:ISM \\
$2.4-2.48 \mathrm{GHz}$ & UHF & $12 \mathrm{~cm}$ & ISM \\
$5.8 \mathrm{GHz}$ & SHF & $5.1 \mathrm{~cm}$ & ISM \\
\hline
\end{tabular}

$\mathrm{RF}$ transmission frequencies (see Table 7) are substantially lower than the frequencies of the photons hitting solar panels (see Table 3). Comparing solar and RF harvesting, we notice that the RF harvested power levels are 4-5 orders-of-magnitudes lower for RF per $\mathrm{m}^{2}$. Despite this seemingly big disadvantage of RF power levels, RF harvesting is useful and represents a practical alternative for the following reasons [24], [4]:

- The state-of-the-art of VLSI CMOS circuits can function at 2-100 $\mu \mathrm{W}$ power level. Ultra-low power consumers of the Application Specific Integrated Circuits (ASICs) type are designed to perform specific SN's tasks and achieve orders-ofmagnitudes power advantages as compared to generic circuits.

- Bearing in mind that RF energy can travel within materials such as plastic, matt glass, paper, etc., SNs can be located in areas where there is no solar, wind or other kind of power. In these cases, RF power harvesting represents a good alternative.

In practice, the following two RF harvesting categories are used [4]:

1. Ambient RF energy harvesting - The ambient energy may come in the form of Wi-Fi, $\mathrm{TV}$, mobile phone, or military broadcasting, as well as directed energy transmission. The ambient RF harvesting circuit accepts the RF energy and charges much larger power storage systems over extended or indefinite periods of time. A typical ambient RF harvesting circuit can generate power levels in the $2 \mu \mathrm{W} / \mathrm{cm}^{2}$ range.

2. Dedicated-source RF energy harvesting - RFID chips remain the most common and ubiquitous use of power harvesting technology that can generate power levels in the 50 $\mu \mathrm{W} / \mathrm{cm}^{2}$ range. RFID is characterized by two-way communication - the transceiver must not only receive data, but also transmit it via reflective backscatter managed by an internal oscillator and signal modulator.

\subsection{RFID}

A Radio Frequency Identification (RFID) system consists of readers (also called interrogators) and tags (or transponders). A reader communicates with the tags in its wireless range and collects information about the objects to which tags are attached. Depending upon their operating principle, tags are classified into three categories: passive, semi-passive, and active.

A passive tag is the least complex and hence the cheapest. It has no internal power source but uses the electromagnetic (EM) field transmitted by a reader to power its internal circuit. It relies not on a transmitter but on "backscattering" to transmit data back to the reader. A semi-passive tag has its own power source but no transmitter and also uses backscattering. An active tag has both internal power supply and an on-tag transmitter [25]. 
Preferable design solutions for WSNs are based on passive RFID. Fig. 16 illustrates the interaction between a reader and a passive tag [26], [4].

Usually, RFIDs are used in the following areas [25], [26]:

1) Supply chain including industrial process automation, tracking of goods, products identification, stock management, etc.

2) Access control to secure locations and equipment, such as office buildings and safes.

3) Transport payment is used for person/vehicle identification or for recording prepaid balances.

4) E-passports when RFID tags store the information contained in passports.

5) Automotive security for ignition keys equipped when RFID is used in most highend cars as an anti-theft measure.

6) Livestock ID used for animal identification for managements and disease control.

7) Automated libraries when RFID is used in streamlining library work-flow including check-in and check-out of books, books inventory (performed without removing books from the shelves) and maintaining a library inventory in real time.

8) Healthcare where RFID covers: a) tracking hospital personnel, equipment, and supplies; b) checking for counterfeit products; c) preventing errors in healthcare administration; and d) maintenance of shared yet secured medical records.

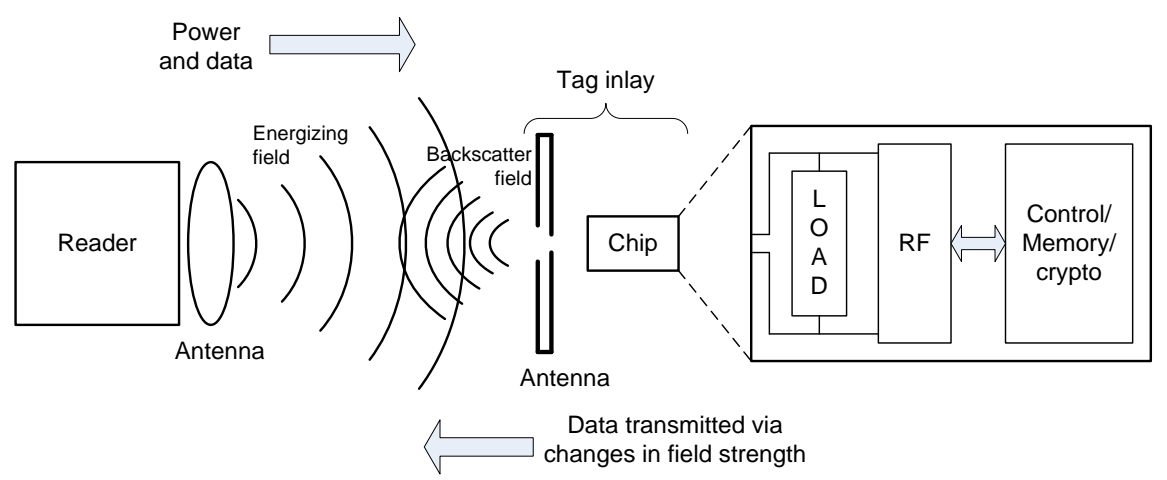

Fig. 16 Reader tag interaction

RFID has great potential for a significant impact on many areas of everyday life. However, a number of obstacles limit its widespread adoption. The main problems in RFID implementations concern reliability, security and privacy.

\subsection{Radio frequency power harvesting}

A radio frequency, RF, power harvesting system captures and converts electromagnetic energy into a usable direct current (DC) voltage. The basic structure of a radio frequency energy harvesting system (see Fig. 17) consists of a receiving antenna, impedance matching network, rectifier/voltage multiplier, and optionally power management. Electromagnetic waves are captured by the antenna, voltage is amplified using the matching circuit, signal is converted to a voltage value thanks to the voltage rectifier, and finally this DC voltage output is adjusted using the multiplier (voltage elevator). Optionally, some schemes include 
a power management building block. Applications deal with load (microcontroller, sensors, radio block) [24].

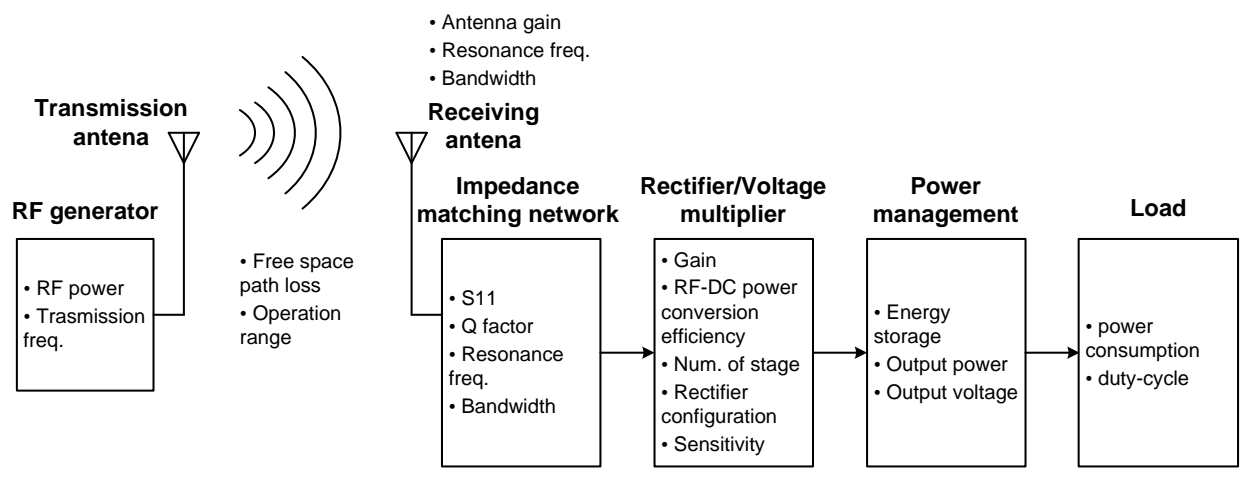

Fig. 17 Block diagram of an RF power harvesting system

In the sequel we will explain, in short, the main design issues related to principle of operation and realization requirement of each RF power harvesting system building block.

An $R F$ antenna can harvest energy from a variety of sources, including broadcast TV signal (ultrahigh frequency (UHF)), mobile phones (900-950 MHz), or Local Area Network $(2.45 \mathrm{GHz} / 5.8 \mathrm{GHz})$, etc.

The loss of power in space can be characterized by free space path loss (FSPL), which is the loss of signal power during propagation in free space. Calculating FSPL requires information about the antenna gain, frequency of transmitting wave, and distance between the transmitter and receiver [24]. The behavior of electromagnetic waves depends upon the distance from the transmitting antenna. These characteristics are categorized into two segments: far-field and near-field. In most applications SNs are located in far-field where the range $(R)$ is higher than $2 D^{2} / \lambda$ ( $D$ is the maximum dimension of the radiator (or diameter of the antenna), and $\lambda$ is the wavelength of the electromagnetic wave). For a transmitter-receiver antenna in the far-field free space, the power propagation at the receiver antenna can be expressed as

$$
P_{R}=\frac{P_{T} G_{T} G_{R} \lambda^{2}}{(4 \pi R)^{2}}
$$

where $P_{R}$ is power at the receiver antenna; $G_{R}$ is receiver antenna gain relative to the isotropic source $(\mathrm{dBi}) ; \lambda$ is the wavelength of the electromagnetic signal, which is equal to the speed of light in vacuum divided by the signal frequency, $\lambda=c / f$; and $k=2 \pi / \lambda$ is the wave number. From the above formula, the FSPL, $P_{L}$ for far-field can be inferred as

$$
P_{L}=\frac{P_{T}}{P_{R}}
$$

In case $f$ is measured in $\mathrm{MHz}$, distance $R$ is measured in $\mathrm{km}$, and gain $G_{T}$ and $G_{R}$ are measured in $\mathrm{dBi}$, the above function becomes 


$$
P_{L}(d B)=20 \log _{10}(f)+20 \log _{10}(R)+32.44-G_{T}-G_{R}
$$

As can be seen from Eq. (9), $P_{L}$ depends on antenna gain, resonance frequency, and bandwidth.

The ratio between the maximum power density of an antenna at a given distance to the power density of an optimal omnidirectional or isotropic antenna at the same distance, radiating the same power, is known as antenna gain $(G)$. Every antenna has its own optimal operation frequency known as resonance frequency (see Fig. 18) [24]. The resonance frequency is determined by the capacitance and inductance characteristics of the antenna. As frequency increases, inductive behavior becomes dominant and capacitance decreases. The frequency at which the inductance and capacitance nullify each other, minimizing the impedance of the antenna, is called the resonance frequency. The bandwidth of an antenna is the range of frequencies in which the antenna can operate efficiently. A wide bandwidth antenna can collect signals from a wider range of frequencies than a narrow bandwidth antenna.

Impedance matching network is used to match the antenna impedance to the rectifier circuit in order to achieve maximum power and improve efficiency, by using coils and capacitors.

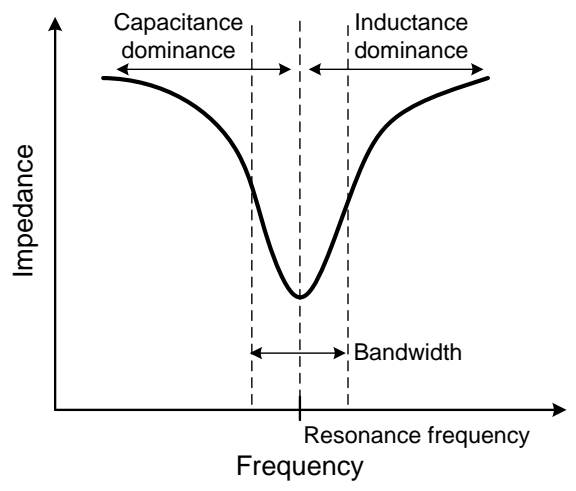

Fig. 18 Correlation between impedance and resonance frequency of an antenna

Rectifier/voltage multiplier is used in order to get a DC signal out of an AC signal and improve the efficiency of the RF-DC power conversion system [4], [27]. In terms of power harvesting application, the RF signal retrieved in the antenna has a sinusoidal waveform. The signal after transformation through impedance matching network would be rectified and boosted to meet the power requirements of the application. To achieve this goal voltage multiplier is used. It is a special type of rectifier circuit that converts and boosts AC input to DC output. In a case where the rectified power is inadequate for the application, there is a need for boosting the output DC by stacking single rectifiers into series, forming the voltage multiplier. Two standard configurations of the voltage multiplier are shown in Fig. 19 where $V_{\text {in }}$ is RF signal. The most fundamental configuration is the Cockcroft-Walton voltage multiplier (Fig. 19a). This circuit's operational principle is similar to the full-wave rectifier but has more stages for higher voltage gain. The Dickson multiplier in Fig. 19b) is a modification of Cockcroft-Walton's configuration with stage capacitors being shunted to 
reduce parasitic effects. Thus, the Dickson multiplier is preferable for small voltage applications.

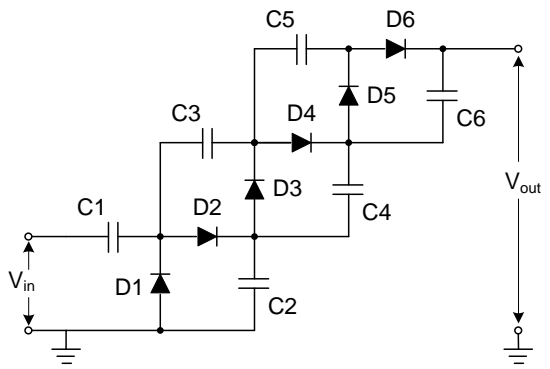

(a)

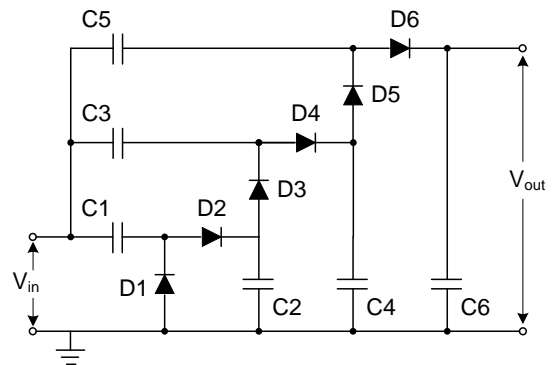

(b)

Fig. 19 Different types of voltage multipliers: (a) Villard/Cockcroft-Walton voltage multiplier, (b) Dickson/Greinacher voltage multiplier

The most popular rectifier used is a modified Dickson multiplier, which has the function of rectifying the radio frequency signal and increases the DC voltage, see Fig 20a) [28]. Moreover, many works have used a complementary metal-oxidesemiconductor (CMOS) technology to replace the diodes, see Fig. 20b).

Typical applications of RF power harvesting are met in medical/healthcare and wireless power harvesting network (IoT/WSN).

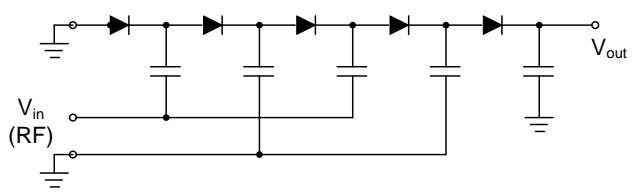

(a)

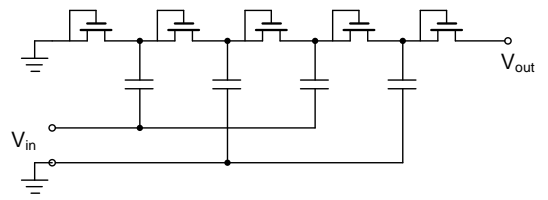

(b)

Fig. 20 Modified Dickson charge pump: (a) diode based 2 stages: $3 \times$ multiplier Dickson charge pump, (b) CMOS based

Schottky diodes were mainly used in early rectifier designs (implemented in energy harvesting systems) due to their low threshold voltage, exponential voltage drop with current, and stable performance under varying temperatures. Nowadays, the Schottky diode remains in use for modern rectifiers, especially for those built with discrete components, since they are often available as surface mount packages and can thus be used in a PCB design. However, many publications have opted not to use Schottky diodes due to their cost, inconsistent process quality, and difficulty to integrate into standard CMOS production. The diode connected transistor was introduced early on as an alternative, but suffers a number of disadvantages when compared to the Schottky diode; transistors have a more significant initial threshold voltage that decreases quadratically, rather than exponentially like the Schottky, and experience more power loss over their nonlinear stages of operation due to the body effect. Lowering this transistor threshold requires establishing a substrate bias appropriate for the transistor's position in the rectifier circuit [4], [28]. 


\section{HYBRID ENERGY HARVESTERS}

Autonomous solar-only/or thermal-only/or vibration-only field systems are susceptible to frequent power interruptions (downtime), because neither solar panels/nor thermal transducers/nor vibration transducers can individually provide continuous power throughout an entire day. Namely, single harvester generator or harvesting single power source may remain insufficient for the energy feed into the systems like electronic devices, biosensors, human, structural and machine health monitoring, and wireless sensor nodes. One possible solution being considered is to harvest energy from various ambient sources, such as light, thermal and vibration energy, supplying power for the WSN. However, these energy sources are not available all the time. In order to harvest energy continuously, it is necessary to design and fabricate a hybrid energy harvester that integrates, for example, from solar panels and piezoelectric vibration generators, enabling energy harvesting from light, thermal, and vibration simultaneously. In general, the basic idea is to scavenge the energy from several energy sources as much as possible, store the energy in a single super-capacitor and discharge it when it is enough to supply the load for an established amount of time. In the past few years, there emerged a number of multi-input energy harvesting systems that have been presented by researchers [29], [30]. A variety of circuit design architectures with various combinations of ambient sources and implementation of CMOS technology are introduced also [31], all with the same goal which is to improve the harvester's performance with the maximum power conversion efficiency and minimal power losses. Hybrid energy harvesting is combining more than one ambient source to generate electrical power out of a single system. By harvesting and combining energy from multiple sources, energy can flow continuously even though one or more sources are absent. In essence, hybrid harvesters [31] that can utilize a combination of solar, piezoelectric, thermal and other kind of power are attractive because these different sources often have complementary availability. Hence, more power can be supplied and the overall system reliability and functionality can be enhanced. The overall behavior of the hybrid energy harvester is depending on the design of each component in the system.

In Fig. 21 a schematic of power harvester which is used to scavenge the energy from two sources, store the energy in a single super-capacitor and discharge it when it is enough to supply the load for an established amount of time [29].

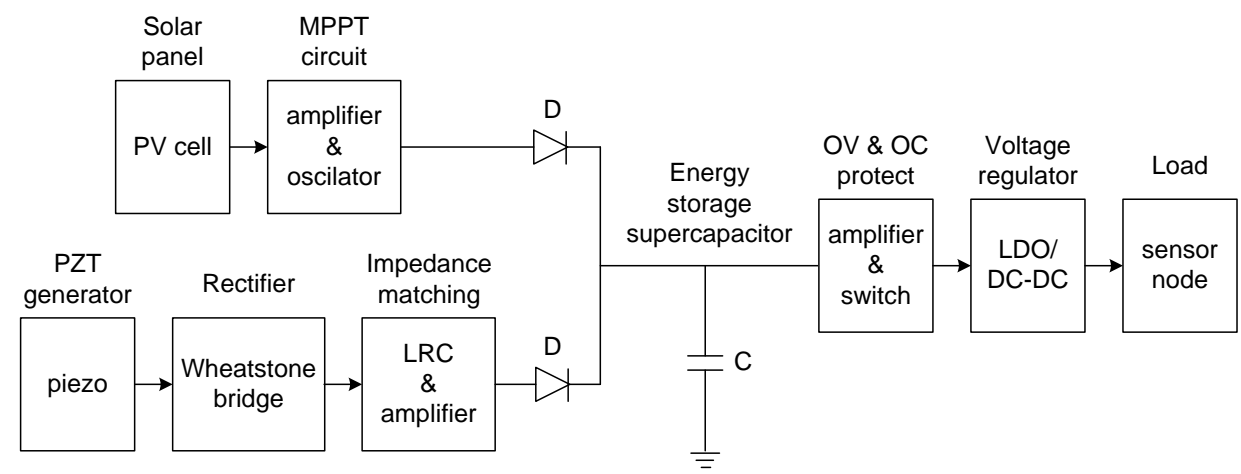

Fig. 21 Electrical scheme of a dual- hybrid energy harvesting system 


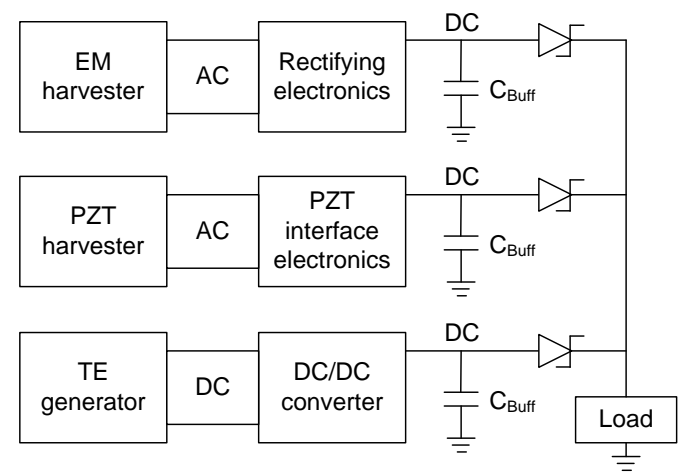

Fig. 22 Structure of triple-hybrid energy harvester

As can be seen from Fig. 21 the harvester consists of an MPPT circuit for ambient light energy storage, an AC-DC rectifying circuit and an impedance matching circuit for vibration energy, energy storage, energy bleed-off and voltage regulator.

Currently, the design and development of a poly-hybrid single-chip harvesting systems that combine solar, vibration, RF, and thermal harvesting outputs at a single load are in the focus of interest of many researchers. In Fig. 22 the structure of one commonly used triple-hybrid energy harvester system is presented [31].

\section{CONCLUSION}

In this paper, the basic principles of energy harvesting technology in recent years are summarized. This technology will play a crucial role in replacing battery (constituent of any remote or mobile device such as wireless sensor node) in the near future. In general, the source of ambient energy must be chosen according to the local environment of the wireless sensor node because no universal ambient energy source exists. Besides the progressive advance in recent years, there is still a variety of options to further optimize the energy harvesting technology with an aim of prolonging the lifetime of a sensor node. It seems to the authors that hybrid energy harvesters realized as a single VLSI IC chip will offer more benefits and will gradually become a reality in the near future. Although this technology still faces many technical problems, overcoming these challenges can lead to a drastic lifetime prolongation of a sensor node.

\section{REFERENCES}

[1] I.F. Akyildiz, M.C. Vuran, Wireless Sensor Networks, John Wiley \& Sons Ltd., Chester UK, 2010.

[2] G. Anastasi, M. Conti, M. Di Francesco, A. Passarella, "Energy conservation in wireless sensor networks: A survey", Ad Hoc Networks, 7 (2009), pp. 537-568.

[3] F. Yang, "Reliable and Time-Constrained Communication in Wireless Sensor Networks", PhD thesis, Ecole doctorale, Informatique et Mathématiques, INSA de Lyon, 2011.

[4] T. Soyata, L. Copeland, W. Heinzelman, "RF Energy Harvesting for Embedded Systems: A Survey of Tradeoffs and Methodology", IEEE Circuits and Systems Magazine, Vol. 16, Issue 1, 2016, pp. 22-57 
[5] Bruce Haug, "Wireless Sensor Nodes Can Be Powered by Temperature Gradients; No Batteries Needed: Harvesting Energy from Thermoelectric Generators", IEEE Power Electronics Magazine, Vol. 4, No. 4, 2017, pp. 24-32

[6] M. Habibzadeh, M. Hassanalieragh, A. Ishikawa, Tolga Soyata, Gaurav Sharma, "Hybrid Solar-Wind Energy Harvesting for Embedded Applications: Supercapacitor-Based System Architectures and Design Tradeoffs", IEEE Circuits and Systems Magazine, Volume 17, Issue 4, 2017, pp. 29-63

[7] G. Nikolic, M. Stojcev, Z. Stamenkovic, G. Panic, B. Petrovic, "Wireless Sensor Node with Low-Power Sensing", Vol 27, No 3 (2014), pp. 435-453

[8] M. K. Stojčev, M. R. Kosanović, L. R. Golubović, "Power management and energy harvesting techniques for wireless sensor nodes", 9th International Conference on Telecommunication in Modern Satellite, Cable, and Broadcasting Services, 2009. TELSIKS '09, pp. 65-72

[9] G. S. Nikolic, M. K. Stojcev, T. R. Nikolic, B. D. Petrovic, G. S. Jovanovic, "Reliable data transfer Rendezvous protocol in wireless sensor networks using 2D-SEC-DED encoding technique", Microelectronics Reliability, Vol. 65, October 2016, pp. 289-309

[10] S. Boisseau, G. Despesse, B. A. Seddik, "Electrostatic Conversion for Vibration Energy Harvesting", Chapter 5 in Small-Scale Energy Harvesting, ed. by M. Lallart, InTech, October 2012, pp. 91-134

[11] Christian Schuss, "Measurement Techniques and Results Aiding the Design of Photovoltaic Energy Harvesting Systems", PhD thesis, 2017, University of Oulu, Faculty of Information Technology and Electrical Engineering, Finland

[12] V. Raghunathan, P. H. Chou, "Design and Power Management of Energy Harvesting Embedded Systems", International Symposium on Low Power Electronics and Design, 2006. ISLPED'06. Proceedings of the 2006, pp. 369-374

[13] L. Mateu, F. Moll, "Review of energy harvesting techniques and applications for microelectronics", VLSI Circuits and Systems II, (2005), ed. by J. F. López, F. V. Fernández, J. M. López-Villegas, J. M. de la Rosa, Proceedings of SPIE Vol. 5837 (SPIE, Bellingham, WA, 2005), pp. 359-373

[14] D. Brunelli, L. Benini, C. Moser, L. Thiele, "An Efficient Solar Energy Harvester for Wireless Sensor Nodes", Design, Automation and Test in Europe, 2008. DATE '08, pp. 1-6

[15] Ryan Mayfield, "The Highs and Lows of Photovoltaic System Calculations", Electrical Construction \& Maintanance, July 2012, av. at http://ecmweb.com/green-building/highs-and-lows-photovoltaic-systemcalculations, accessed on May, 2018.

[16] Nathan Bourgoine, "Harvest Energy from a Single Photovoltaic Cell", Linear Technology, Journal of Analog Innovation, Volume 21, Number 1, 2011, pp. 1-6

[17] M. J. Guan, W. H. Liao, "On the efficiencies of piezoelectric energy harvesting circuits towards storage device voltages", Smart Materials and Structures, Vol. 16, No. 2, 2007, pp. 498-505, IOP Publishing

[18] Michael Whitaker, "Energy Harvester Produces Power from Local Environment, Eliminating Batteries in Wireless Sensors", Linear Technology, Journal of Analog Innovation, Vol. 20, No. 1, 2010, pp. 1-36

[19] Yogesh K. Ramadass, Anantha P. Chandrakasan, "A Battery-Less Thermoelectric Energy Harvesting Interface Circuit with $35 \mathrm{mV}$ Startup Voltage", IEEE Journal of Solid-State Circuits, Vol. 46, No. 1, 2011, pp. 333-341

[20] Kjartan Bjarni Kristjánsson and Steinar Porvaldsson, "Test System to Evaluate Energy-Harvesting Technologies for Wireless Sensors”, Master's thesis in Embedded Electronic System Design, Department of Computer Science and Engineering, Chalmers University of Technology, Gothenburg, Sweden, 2016

[21] Piotr Dziurdzia, "Modeling and Simulation of Thermoelectric Energy Harvesting Processes", Sustainable Energy Harvesting Technologies - Past, Present and Future, Ed. by Y. K. Tan, InTech, 2011, pp. 109-128

[22] David Salerno, "Ultralow Voltage Energy Harvester Uses Thermoelectric Generator for Battery-Free Wireless Sensors", Linear Technology, Journal of Analog Innovation, Vol. 20, No 3, 2010, pp. 1-11

[23] Vaughn Nelson, "Wind Energy: Renewable Energy and the Environment", Second Edition, 2013, CRC Press, Boca Raton, USA

[24] L.G. Tran, H.K. Cha, W.T. Park, "RF power harvesting: a review on designing methodologies and applications", Micro and Nano Systems Letters, Dec. 2017, 5:14

[25] V. Chawla, D. S. Ha, "An Overview of Passive RFID”, IEEE Communications Magazine, Applications \& Practice, Volume: 45, Issue: 9, September 2007, pp. 11-17

[26] P. Krishna, D. Husak, "RFID Infrastructure - A Technical Overview", White Paper, published in IEEE Applications \& Practice, Sept. 2007, Vol. 1, No. 2, pp. 1-18

[27] U. Guler, M. Ghovanioo, "Power Management in Wireless Power-Sipping Devices: A Survey", IEEE Circuits and Systems Magazine, Vol. 17, No.4, 2017, pp. 64-82

[28] Yuan Fei, CMOS Circuits for Passive Wireless Microsystems, 2010, Springer, New York

[29] H. Yu, Q. Yue, J. Zhou, W. Wang, “A Hybrid Indoor Ambient Light and Vibration Energy Harvester for Wireless Sensor Nodes”, Sensors, 2014, Vol. 14, pp. 8740-8755 
[30] T. N. T. Mohamad, J. Sampe, D. D. Berhanuddin, “Architecture of Micro Energy Harvesting Using Hybrid Input of RF, Thermal and Vibration for Semi-Active RFID Tag”, Engineering Journal, 21(2), 2017, pp. 183-197

[31] H. Uluşan1, S. Chamanian1, W. M. P. R. Pathirana, Ö. Zorlu, A Muhtaroğlu, H Külah, “Triple Hybrid Energy Harvesting Interface Electronics”, Journal of Physics: Conference Series, Vol. 773, 2016, 012027, IOP Publishing 